\title{
Oxygen transfer into activated sludge with high MLSS concentrations
}

\author{
Dr.-Ing. Jörg Krampe, Prof. Dr.-Ing. Kh. Krauth, Institute for Sanitary Engineering, \\ Water Quality and Solid Waste Management, University of Stuttgart, Bandtäle 2, \\ 70565 Stuttgart, Germany, joerg.krampe@iswa.uni-stuttgart.de
}

\begin{abstract}
In this report, tests on the impact of the sludge properties on the oxygen transfer at low and high solids contents are presented. Additional to the oxygen transfer tests, the activated sludge was intensively analysed to examine the changes of the $\alpha$-factor in relation to the sludge properties (rheology, EPS, CST etc.). The $\alpha$-factor did strongly decrease in all sludge types at increasing MLSS or increasing viscosity, respectively.

In the second test stage, the impact of the aeration system was examined in detail. For these tests, the same sludge from a membrane bioreactor was used throughout. Apart from the impact of the power density in the reactor and the specific air throughput, the main focus was on the economic efficiency of the examined systems in cases of high MLSS. It became apparent that up to solids contents of $18 \mathrm{~g} / \mathrm{l}$ the fine-bubble aeration is the most economically efficient method.
\end{abstract}

\section{KEY WORDS}

Aeration systems, membrane bioreactor, sludge properties, oxygen transfer

\section{INTRODUCTION}

The pre-requisite of all aerobic biological purification processes is the sufficient supply of the biomass with oxygen. For the municipal wastewater treatment in Germany using the activated sludge process, fine-bubble aeration systems have been used almost exclusively in recent years, because these methods make for the best oxygen transfer efficiency.

Since the first examinations on membrane bioreactors, several authors have concurrently reported about a considerable deterioration of the oxygen transfer in cases of increased solid contents in the biological reactor, which leads to a steep increase of the energy demand for the sufficient supply of the biomass with oxygen. In order to establish membrane bioreactors as a new technology with all its advantages for the re-use of process water and water pollution control (germ retention, retention of endocrine disrupters etc.), this problem must be minutely observed. The deterioration of the transfer rate in case of increasing solids contents can be mainly traced back to the increased bubble coalescence caused by the changed rheology of the sludge and to an increased production of extracellular polymeric substances (EPS).

\section{THEORETICAL BASICS}

The basis for the description of the oxygen transfer, that is of the increasing oxygen concentration in the water during the respective period, is the following principal equation: 


$$
\frac{\mathrm{dC}}{\mathrm{dt}}=\mathrm{k}_{\mathrm{L}} \cdot \mathrm{a} \cdot\left(\mathrm{C}_{\mathrm{S}}-\mathrm{C}\right)
$$

According to this equation, the relevant factors are the concentration difference between the gaseous and the liquid phases, the oxygen transfer coefficient $(\mathrm{k} L)$ and the boundary surface (a). The concentration difference can be influenced by using pure oxygen or by increasing the pressure in the reactor. In both cases, the partial pressure of the oxygen increases and thus the solubility of the oxygen in the liquid phase. The product of the transfer coefficient $\left(\mathrm{kL}_{\mathrm{L}}\right.$ ) and the specific boundary surface $(\mathrm{a})$ is in practice summed up as the overall aeration coefficient (kLa). In contrast to the single factors, this coefficient can be measured very easily. The overall aeration coefficient (kLa) can be influenced by a number of parameters. In reference literature (e.g. Henzler, 1982 or Zlokarnik, 2001), the following influence parameters are mentioned:

- gas throughput per reactor cross section (superficial velocity v)

- net energy input into the reactor (power density P/V)

- substance properties (such as diffusion coefficient, viscosity)

The impact of the single factors depends mainly on the aeration system and the aerated medium. Information about this impact can be gained from the presentation of the measuring results in sorption characteristics. One distinguishes between dimensionless and dimensional presentations. The dimensional form is commonly used for the results of purewater tests, the dimensionless presentation for tests with variable viscosity, as the impact of the viscosity can be considered very well in this method. In this report, only the dimensional presentation according to Judat (1981, quoted in Henzler, 1982) is discussed:

$$
\mathrm{kLa} \sim\left(\frac{\mathrm{P}}{\mathrm{V}}\right)^{\mathrm{a}} \cdot \mathrm{v}^{\mathrm{b}}
$$

With these sorption characteristics, it is possible to determine those parameters which influence the mass transfer and their sensitivity. In some cases it is even possible to predict the kLa-value for the respective substance system. Whereas in tests with pure water the superficial velocity $(v)$ has a higher influence than the power density $(P / V)$, the relations change with increasing viscosity of the medium (Grohmann, 1993).

In the following, the $\alpha$-factor and the oxygen transfer efficiency are used to describe the mass transfer. The $\alpha$-factor describes the change of the mass transfer in the activated sludge compared to pure water. The oxygen transfer efficiency (OP) is the quotient of oxygen input $(\mathrm{OC})$ and the energy uptake $(\mathrm{P})$ of the aeration system including the mixing implements.

\section{DESCRIPTION OF THE PILOT PLANT AND THE ANALYSES}

The pilot plant used for the test series on the oxygen transfer was an approx. $4 \mathrm{~m} \mathrm{high,}$ round Plexiglas container with a diameter of $0,80 \mathrm{~m}$. At a filling level of $3,00 \mathrm{~m}$, the liquid volume to be aerated amounted to $1,4 \mathrm{~m}^{3}$. The measuring of the air amounts was achieved with flow-meters of different sizes. For the conversion of the air amounts calculated thus into norm cubic meters, additional pressure and temperature measuring devices were installed. The air amount was set via a needle valve. The kLa-values were determined using the adsorption method according to the definitions of the ATV (ATV, 1996). For measuring, three rapid-response oxygen electrodes were installed at different levels.

CIWA Publishing 2003. The definitive peer-reviewed and edited version of this article is published in Water Science \& Technology, Volume 47, Issue 11, 297-303, 2003, doi:10.2166/wst.2003.0618 and is available at www.iwapublishing.com. This is the accepted version. 
In the tests, different aeration systems were examined which should cover a large section of the technologies available on the market. In the tests, hollow stirrers or submerged aerators were not used, as these methods had yielded worse results in the examinations run by Grohmann (1993) than the fine-bubble aeration with additional stirring implement, which had been tested in those test series as well. In the analyses, the following aeration systems were considered:

- fine-bubble aeration with ceramic domes

- injector for compressed air

- Drausy aerator hose for pure oxygen

- injector for pure oxygen

- fine-bubble aeration combined with a stirring implement

Whenever compressed air was used, the aeration systems were run uniformly at $10,3 \mathrm{~m}^{3} \mathrm{~N} / \mathrm{h}$. Because of the higher partial pressure of pure oxygen, the pure oxygen systems were run with only one fifth of the gas volume flow. The energy uptake of the respective aggregates were calculated theoretically and then incremented by a common efficiency degree. This was necessary because the energy uptake of semi-technical test plants cannot be representatively be transferred to industrial plants.

During the variation of the activated sludge types, a large number of parameters was analysed. Apart from known parameters such as MLSS and MLVSS, the viscosity, the capillary suction time (CST), the polymer contents, the surface tension, and typical single components of the extracellular polymeric substances (EPS) were analysed.

The viscosity was determined in a rotational viscometer with double-gap system. As activated sludge is a non-Newtonian liquid with pseudoplastic (shear-thinning) properties (Dick and Ewing, 1967), flow curves were recorded and evaluated according to the approach by Herschel and Bulkley:

$$
\tau=\tau_{\mathrm{gr}}+\mathrm{K} \cdot \mathrm{D}^{\mathrm{n}}
$$

According to this approach, the rheological behaviour of the activated sludge can be characterised by the three structural parameters $\tau_{\mathrm{gr}}, \mathrm{K}$ and $\mathrm{n}$. This approach has also been used by Günder (2001), who minutely discussed the importance of the single parameters. The structural parameters can be calculated from the flow curves with the help of a nonlinear regression calculation. The information about these parameters can then be used to determine the representative viscosity $\left(\eta_{r}\right)$ for a defined shear rate (D).

For the CST measuring, a reservoir with a filter surface of $254,47 \mathrm{~mm}^{2}$ (Type A) and the filter carton No. 2668 by Schleicher \& Schüll was used. For the determination of the polymer contents, a method described by Steinmetz (1996) was used, which is in turn based on an approach described by Glasgow et al. (1983). The extraction of the EPS was run following the methodology of Frolund et al. (1996).

\section{DESCRIPTION OF THE EXAMINED SLUDGES AND THEIR IMPACT ON THE OXYGEN TRANSFER}

In the first phase of the project, activated sludges with high solid contents (> $15 \mathrm{~g} / \mathrm{l})$ from different wastewater treatment plants and semi-technical pilot plants were examined. The aeration was done respectively with an injector and with fine-bubble aeration. All sludge CIWA Publishing 2003. The definitive peer-reviewed and edited version of this article is published in Water Science \& Technology, Volume 47, Issue 11, 297-303, 2003, doi:10.2166/wst.2003.0618 and is available at www.iwapublishing.com. This is the accepted version. 
types were gradually diluted, so that in a test sequence the development of the $\alpha$-factor could be evaluated via the entire relevant solids contents. Additional to the oxygen transfer tests, the analyses of the activated sludges described above were run, in order to observe the changes of the $\alpha$-factor in dependence on the sludge properties. In all sludges, the $\alpha$ factor strongly decreased with the increasing MLSS contents or increasing viscosity, respectively. Crucial differences in the development of the $\alpha$-factor could be determined only for industrial sludges with high salt contents.

At first, the sludge parameters were inter-correlated. In this way, problems of the sludge analysis could be discovered. For instance, the EPS determined in an external laboratory could only partly be used for the evaluation because the comparison with the results of the polymer determination according to Steinmetz (1996) showed considerable differences in parts. These differences could be traced back to problems with the transport of the samples. Particularly sludges from plant with higher sludge loads increasingly produced slime coatings during the 24-hour-transport, which leads to an increase of the EPS contents. For a more detailed description of this relation and for details on the sludge analysis, please consult Krampe (2001).

Figure 1 compares the $\alpha$-factors determined in the oxygen transfer tests with the MLSS. The diagram also contains information about the interrelation found by Günder (2001) and a newly calculated exponent based on the measuring used in this project. Furthermore, the diagram contains results found by Fröse (2001) also for fine-bubble aeration.

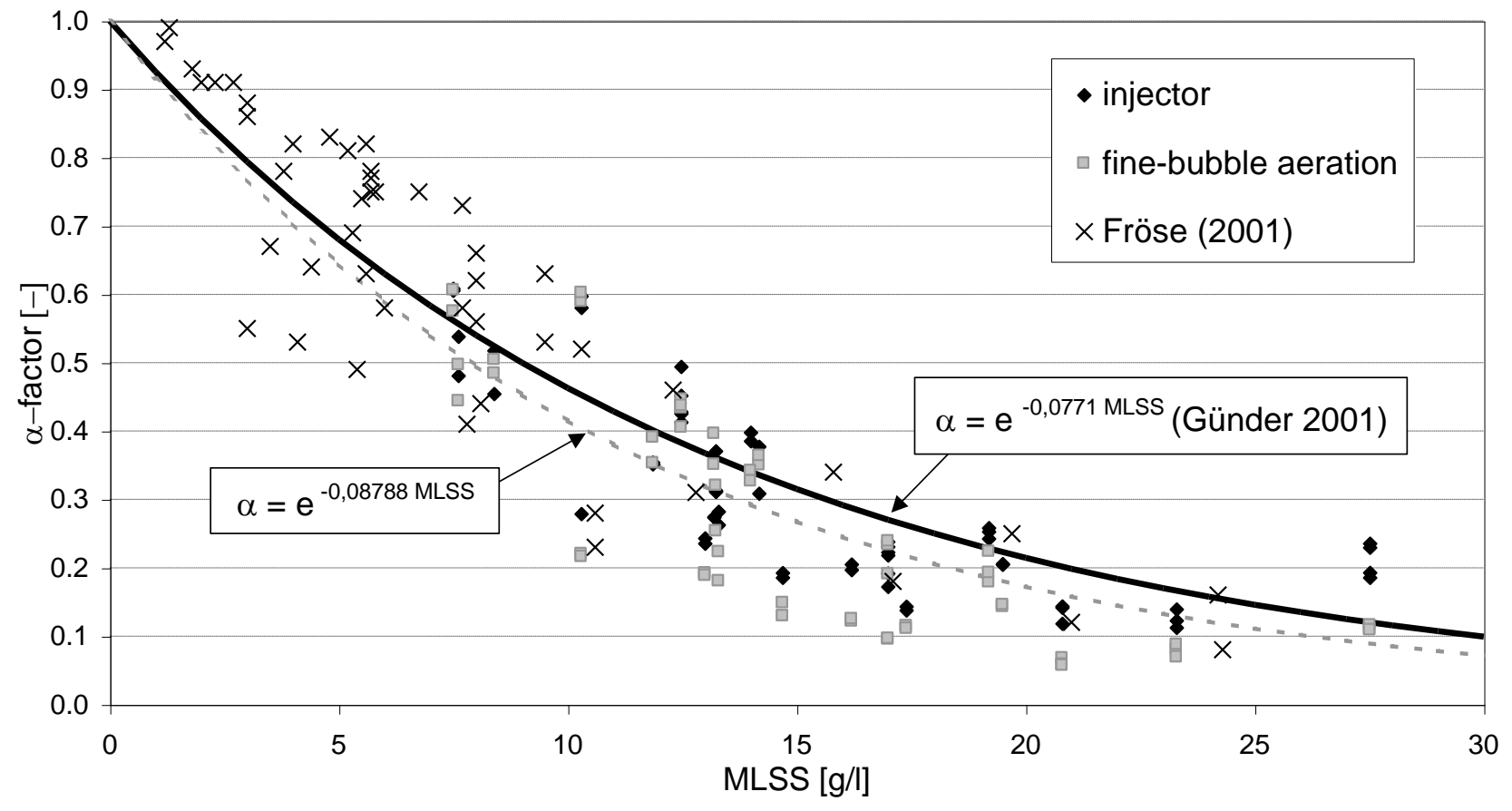

Figure 1: Comparison of the determined $\alpha$-factor for fine-bubble and injector aeration and the MLSS

Figure 1 clearly shows that there is a relation between the $\alpha$-factor and the solids contents. Differences in the dependence of the $\alpha$-factor on the aeration system, however, cannot be found for fine-bubble aerator and injector. 
The connection found within the frame of this project makes for slightly lower $\alpha$-factors than those determined by Günder (2001). As he did consider also surface aerator and middle-sized bubble aerators in his examinations, the difference can easily be explained. Particularly surface aerators show relatively high $\alpha$-factors, and reach less favourable transfer rates than, for instance, fine-bubble aeration.

Rosenberger et al. (2000) and Günder (2001) state that there is a connection between $\alpha$ factor and viscosity. The only difference lies in the selection of the shear rate for the comparison. For the representative viscosity, Günder (2001) chose a shear rate of $401 / \mathrm{s}$ and justifies this with the bubble size and bubble rising velocity. Rosenberger et al. (2000), however, chose the representative viscosity at a shear rate of $801 / \mathrm{s}$. Below, the $\alpha$-factor is compared to the representative viscosity only for a shearing rate of $401 / \mathrm{s}$ (Figure 2), as the results for $801 / \mathrm{s}$ develop in a rather similar tendency.

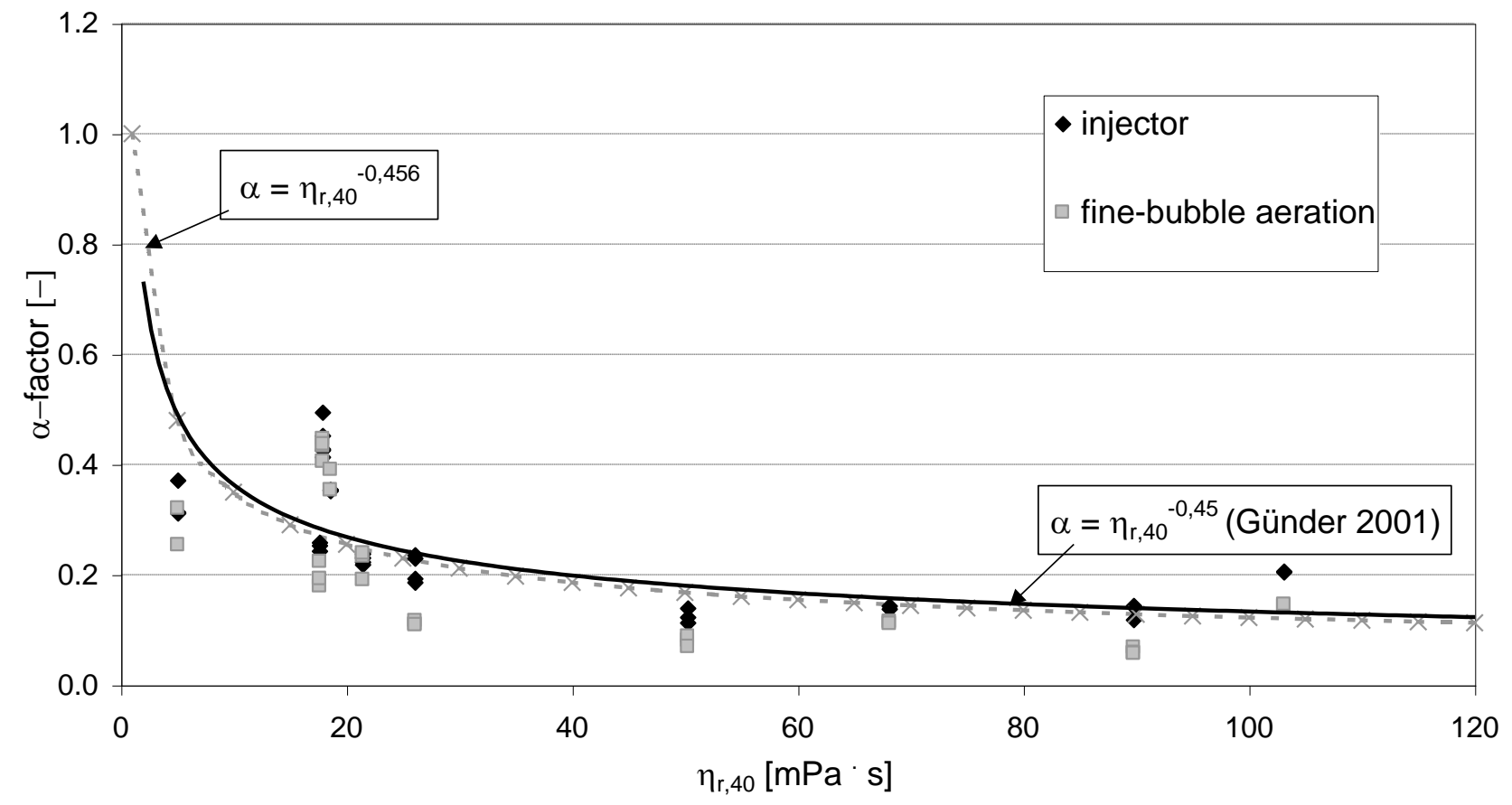

Figure 2: Connection between representative viscosity at a shearing rate of $401 / \mathrm{s}$ and the determined $\alpha$-factors

Figure 2 shows the relation formulated by Günder (2001) as an uninterrupted black line. Applying the approach used by Günder, an almost identical coefficient could be determined from the measuring values found gained during the project.

There is a more distinct relation between the representative viscosity and the $\alpha$-factor than between the MLSS and the $\alpha$-factor. Higher scattering appears only at lower viscosity degrees $(<20 \mathrm{mPa} \cdot \mathrm{s})$. The viscosity degrees determined there, however, are based on only a few measuring points and represent the lower measuring area of the applied double-gap system.

\section{DESCRIPTION OF THE EXAMINED AERATION SYSTEMS AND THEIR IMPACT ON THE OXYGEN TRANSFER}

In the second test phase, the impact of the aeration system was examined in closer detail. For this phase, the same sludge from a membrane bioreactor was used throughout. This OIWA Publishing 2003. The definitive peer-reviewed and edited version of this article is published in Water Science \& Technology, Volume 47, Issue 11, 297-303, 2003, doi:10.2166/wst.2003.0618 and is available at www.iwapublishing.com. This is the accepted version. 
sludge was recirculated into the membrane reactor during the changes of the aeration systems and fed with pre-treated wastewater. As further aeration systems, the ones described above were used. The evaluation of the results was run using sorption characteristics according to Judat (1981), in order to have a closer look at those parameters which influence the kLa-value, and via the oxygen transfer efficiency, in order to compare the systems in regard to their economic efficiency.

Figure 3 shows examples of the results gained from the pure water tests in dimensional form, compared to the results of another project (Grohmann, 1993). For pure water tests, it is not necessary to consider the viscosity, so the dimensional form can be used.

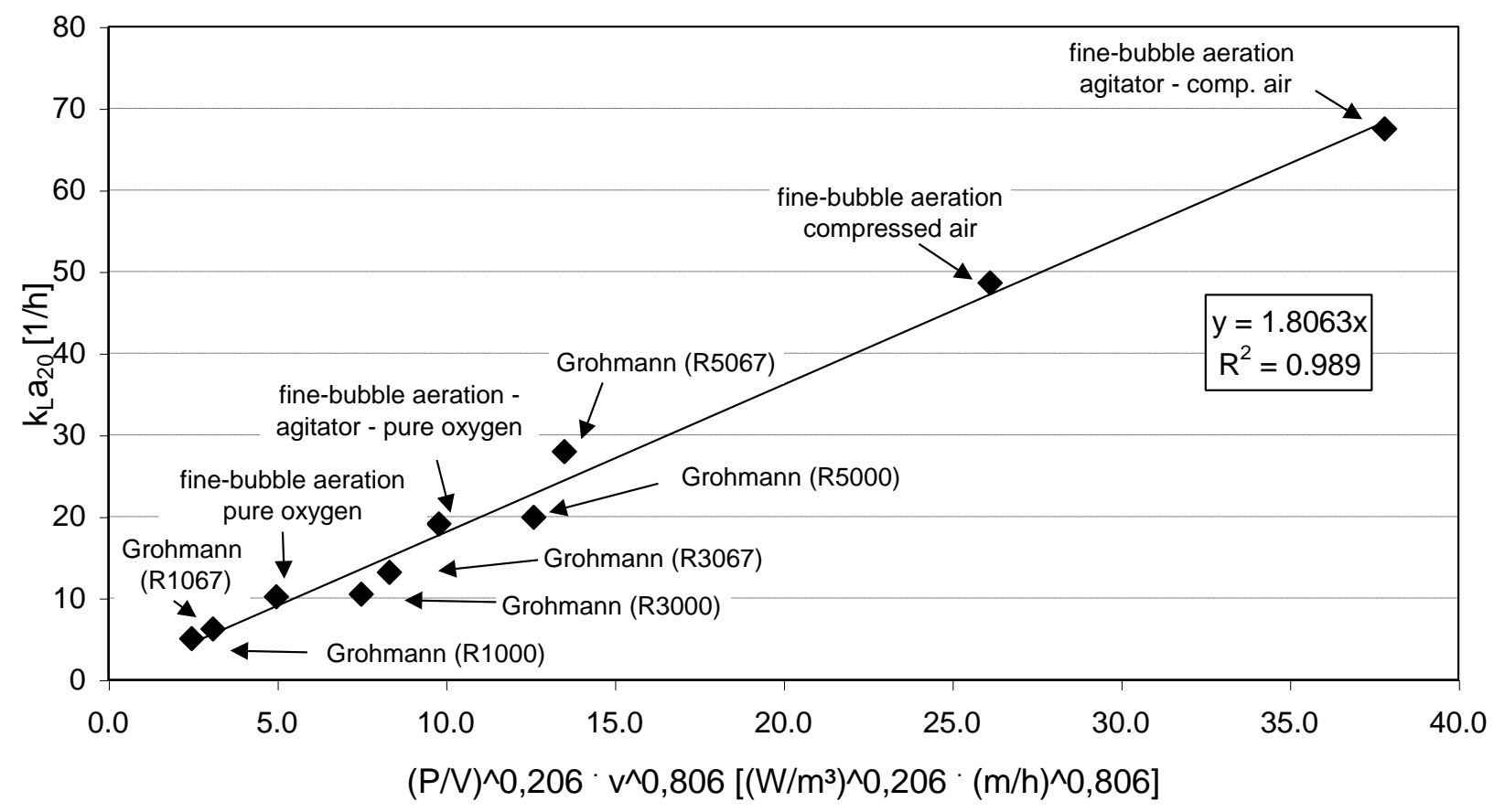

Figure 3: Comparison of the ascertained with reference literature values from a project on aerobic thermophile sludge stabilisation (Grohmann, 1993)

The presentation in the common sorption characteristics was possible also for the tests with activated sludges. Apart from the principal understanding of the connections, the tests were geared to check the economic efficiency of the different aeration systems. The oxygen transfer efficiency for the systems was entered via the solid contents. The MLSS was selected because it can be estimated already during the plant planning phase. In contrast, such an early estimation is not possible for the viscosity.

The determination of the oxygen transfer efficiency was run on the basis of the theoretical energy uptake of the necessary aggregates, to take into account the low efficiency degree of the single aggregates on a semi-technical scale. The comparison with reference literature results from actually realised plants shows that the results determined in this way are plausible. Figure 4 presents the comparison of the oxygen transfer efficiency of different aeration systems via the solids contents in the reactor. 


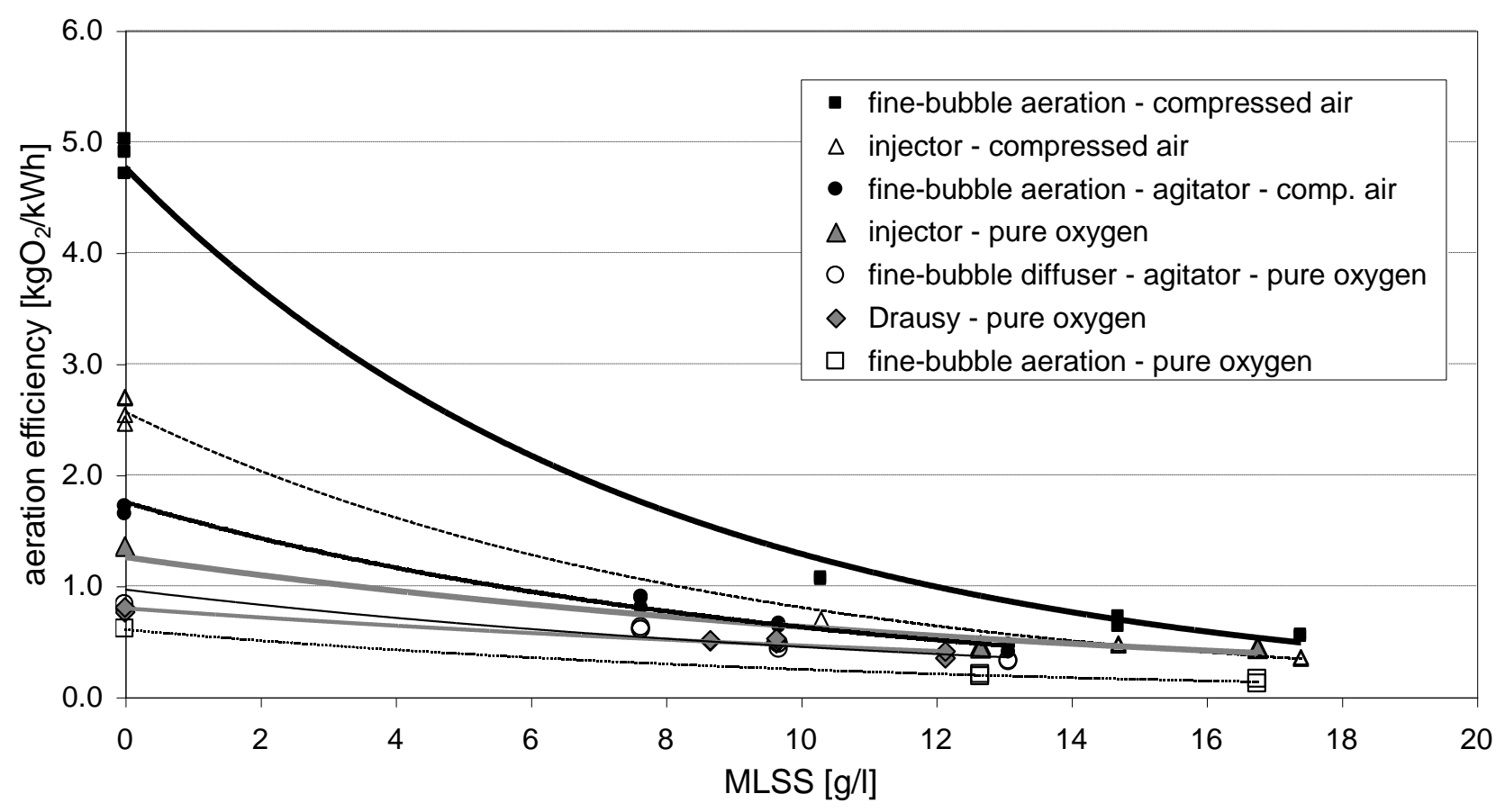

Figure 4: Comparison of the oxygen transfer efficiency of different aerator systems via the solids contents

It becomes apparent that in the examined range up to $18 \mathrm{~g} / \mathrm{l} \mathrm{MLSS}$ the fine-bubble aeration is the most economically efficient system, but also that the systems converge with increasing solid contents. The viscosity of the activated sludge increases with increasing solids contents and the necessary energy input to create turbulent flows increases. At lower solids contents, the energy input through the injected air is sufficient to create a turbulent flow. In this case, the provision of oxygen and of flow energy is achieved through one aggregate (blower) and is thus very economic. It can be assumed that in case of further increasing solids contents systems with a separate circulating pump prove to be the more economically efficient systems, because stirring implements and pumps reach better efficiency degrees than blower. Because of the complicated hydro-dynamic relations, any extrapolation of the results for these areas is not permissible.

\section{CONCLUSIONS}

In order to examine the impact of the sludge properties, oxygen transfer tests were run with different activated sludges and different aeration systems. The sludge was evaluated in regard to MLSS, viscosity, polymer contents, EPS components, and capillary suction time. From an analytical point of view, the results on the capillary suction time were not suitable to describe the sludge properties at solids contents about $20 \mathrm{~g} / \mathrm{l}$. Favourable parameters to describe the relations are the solid contents and the viscosity, with the viscosity being the reason for the deterioration of the mass transfer. In this respect, one problem is the choice of the shearing difference to determine the viscosity in dependence on the oxygen input and the aeration system.

The description of the results could be achieved for all aeration systems via sorption characteristics under consideration of the viscosity, the power density in the reactor, and the specific gas velocity. It was possible to correlate the found results with the sorption characteristics from other examinations. The discussion of the oxygen transfer efficiency for the 
different aeration systems in the examined range up to $18 \mathrm{~g} / \mathrm{l}$ showed that the fine-bubble aeration is the most economically efficient aeration system. Because of the complicated hydro-dynamic relations, however, the results should not be extrapolated to higher solids contents.

\section{ACKNOWLEDGEMENTS}

The authors would like to thank the German Research Association (DFG) for the financial support of the project, the Department of Aquatic Microbiology of the Gerhard-MercatorUniversity at Duisburg (Prof. Dr. H.-C. Flemming) for the EPS analyses, and the owners of the numerous wastewater treatment plants for supplying the examined sludges.

\section{REFERENCES}

ATV (1996). Merkblatt ATV - M 209, Messung der Sauerstoffzufuhr von Belüftungseinrichtungen in Belebungsanlagen in Reinwasser und in belebtem Schlamm, Abwassertechnische Vereinigung

Dick, R.J., Ewing, B.B. (1967) The rheology of activated sludge, JWPCF, (39)4, $543-560$

Fröse, G. (2001). Praxiserfahrungen mit dem ATV-Merkblatt M 209 und Vorstellung des neuen europäischen Norm-Entwurfes DIN EN 12255-15 zur Messung der Sauerstoffzufuhr in Reinwasser, Schriftenreihe WAR, Heft 134, S. 57 - 70

Frolund, B., Palmgren, R., Keiding, K., Nielsen, P.H. (1996). Extraction of Extracellular Polymers from Activated Sludge using a Cation Exchange Rasin, Water Research, 30, pp. $1749-1758$

Glasgow, L.A., Pollock, R.J., Barkley, W.A. (1983). Particle Size Reduction Breakage in Biological Wastewater Treatment, Biotechnol. Bioeng., XXV, pp. $901-918$

Grohmann, W. (1993). Vergleichende Untersuchungen von Belüftungs- und Durchmischungssystemen zur bioverfahrenstechnischen Optimierung der aerobthermophilen Stabilisation (ATS), Schriftenreihe WAR, Heft 73

Günder, B. (2001). The Membrane Coupled-Activated Sludge Process in Municipal Wastewater Treatment, Technomic Publishing Company Inc., Lancaster

Henzler, H.J. (1982). Verfahrenstechnische Auslegungsunterlagen für Rührbehälter als Fermenter, Chem.-Ing.-Tech., Nr. 5, S. $461-476$

Krampe, J. (2001). Das SBR-Membranbelebungsverfahren, Stuttgarter Berichte zur Siedlungswasserwirtschaft, Band 163, Oldenbourg Verlag, München

Rosenberger, S., Kubin, K., Kraume, M. (2000). Vorteile und Grenzen des Betriebs von Membranbioreaktoren bei hohem TS-Gehalt, 3. Aachener Tagung, Siedlungswasserwirtschaft und Verfahrenstechnik

Steinmetz, H. (1996). Einfluss von Abwasserinhaltsstoffen, Stoffwechselprozessen und Betriebsparametern von Belebungsanlagen auf den Sauerstoffeintrag in AbwasserBelebtschlamm-Gemische, Dissertation an der Universität Kaiserslautern

Zlokarnik, M. (2001). Stirring: Theory and Practice, Wiley-VCH Verlag, Weinheim

\section{CONTACT}

Dr.-Ing. Jörg Krampe

Institute for Sanitary Engineering, Water Quality and Solid Waste Management

Department for Wastewater Technology

Bandtäle 2

70569 Stuttgart, Germany

Tel.: ++49 711 685-5420

CIWA Publishing 2003. The definitive peer-reviewed and edited version of this article is published in Water Science \& Technology, Volume 47, Issue 11, 297-303, 2003, doi:10.2166/wst.2003.0618 and is available at www.iwapublishing.com. This is the accepted version. 
Fax: ++49 711 685-3729

e-mail: joerg.krampe@iswa.uni-stuttgart.de

CIWA Publishing 2003. The definitive peer-reviewed and edited version of this article is published in Water Science \& Technology, Volume 47, Issue 11, 297-303, 2003, doi:10.2166/wst.2003.0618 and is available at www.iwapublishing.com. This is the accepted version. 